\title{
Instrumental methods for evaluating food texture
}

\author{
By P. Sherman, Unilever Research Laboratory Colworth/Welwyn, The Frythe, \\ Welwyn, Herts.
}

\section{Introduction}

Food texture has been defined in so many different ways that it would be useful at the outset to indicate the context in which the phrase will be used here. An acceptable definition must cover instrumental and sensory (visual, touch, oral) evaluations of texture, and also the interrelationship between the two methods of evaluation. In order to meet these requirements a definition which resembles that introduced by Szczesniak ( 1963 ) is proposed, namely texture is the composite of those properties which arise from the structural elements of the food and the manner in which it registers with the physiological senses (Sherman, 1970). This definition indicates that texture is not a single measurable property but a composite of many properties.

Before deciding which instrumental method to select for evaluating food texture the following points should be considered.

(a) Are data required about the static structure of the food, i.e. employing test conditions which produce only slight structural alteration?

(b) Are data required about the way in which the food will behave under practical usage conditions, i.e. employing more drastic test conditions than under (a)?

(c) Would it suffice to use an empirical method which vaguely simulates the mechanical action associated with product usage?

Tests which provide quantitative information about food texture are usually time-consuming and require rather sophisticated equipment. Consequently, they have not been used extensively and the emphasis has been on the application of semiquantitative or empirical tests. The latter type of test, however, is useful only for repetitive routine testing where differences between samples need to be recognized but not identified.

The present discussion will be restricted to some of the quantitative and semiquantitative methods which have been used to study the static structure, and performance in usage, of foods. These are listed in Tables I and 2 along with references to the more recent publications which provide data on the foods to which they have been applied.

\section{Quantitative methods for studying the static structure of foods}

Test methods may involve the application of stress or strain on a continuoustime basis, or intermittently as in dynamic testing. Four methods (Table I) which depend upon the application of a constant low shear stress will be described. In all four test methods the strain is measured at different times after the application of the shear stress and by analysis of the curve which is obtained (by plotting 


\section{Table I. Creep compliance-time studies with foods}

Technique

Parallel plate viscoelastometer

Compression between parallel plates

Extension

Coaxial cylinder viscometer

Applications
Heat-coagulated fish paste
Frozen ice cream
Cake
Margarine, butter
Fruit, vegetables
Bread
Margarine, butter
Noodles
Hydrocolloid gels
Meat
Dough
Melted ice cream
Cream

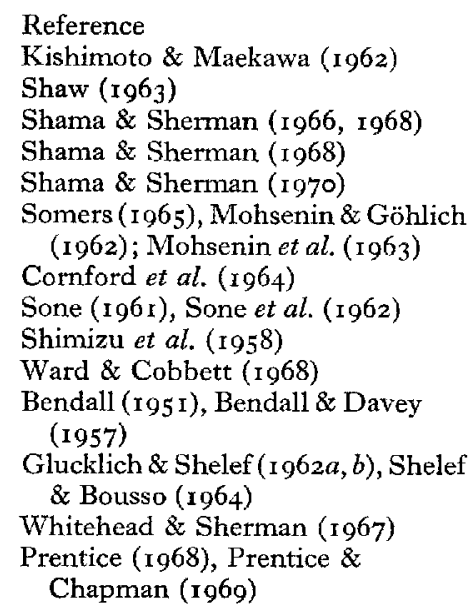

strain against time) the texture of the sample can be defined as the sum of several physical measurements.

Many food materials are viscoelastic, so that they exhibit some of the properties of both solids and liquids when subjected to a shear stress. Provided a linear viscoelastic response is observed, i.e. the stress increases linearly with shear, the following method of analysis can be applied.

\section{Theory of creep compliance-time studies}

The shear stress can be applied in simple shear, in compression, or in extension, but in all three cases a plot of the ratio of strain: shear stress, which is known as the creep compliance, against time gives a curve with the general form shown in Fig. $r$. It can be subdivided into three characteristic regions.

(I) A region of instantaneous elastic compliance (AB) in which linkages between the basic units of the microstructure are stretched elastically. If the shear stress were removed at $B$ then the sample would recover its original structure and dimensions. The instantaneous elastic compliance $\mathrm{J}_{0}$ is given by

$$
\mathrm{J}_{0}=\frac{\epsilon_{0}(\mathrm{t})}{\mathrm{p}}=\frac{\mathrm{I}}{\mathrm{E}_{\mathrm{0}}},
$$

where $\epsilon_{0}(t)$ is the instantaneous strain at small values of the time $t, p$ is the shear stress, and $\mathrm{E}_{\mathbf{0}}$ is the instantaneous elastic modulus.

(2) A region of retarded elastic compliance (BC) in which the rate of strain decreases gradually owing to rupture of linkages. At the lower end of the time-scale associated with this region, few linkages remain permanently broken, but at the higher end, the number of linkages which do not reform is much larger. Normally, all linkages in a sample do not have identical strength; instead, there is a spectrum of strengths with the weaker linkages breaking after shorter times than the stronger linkages. 


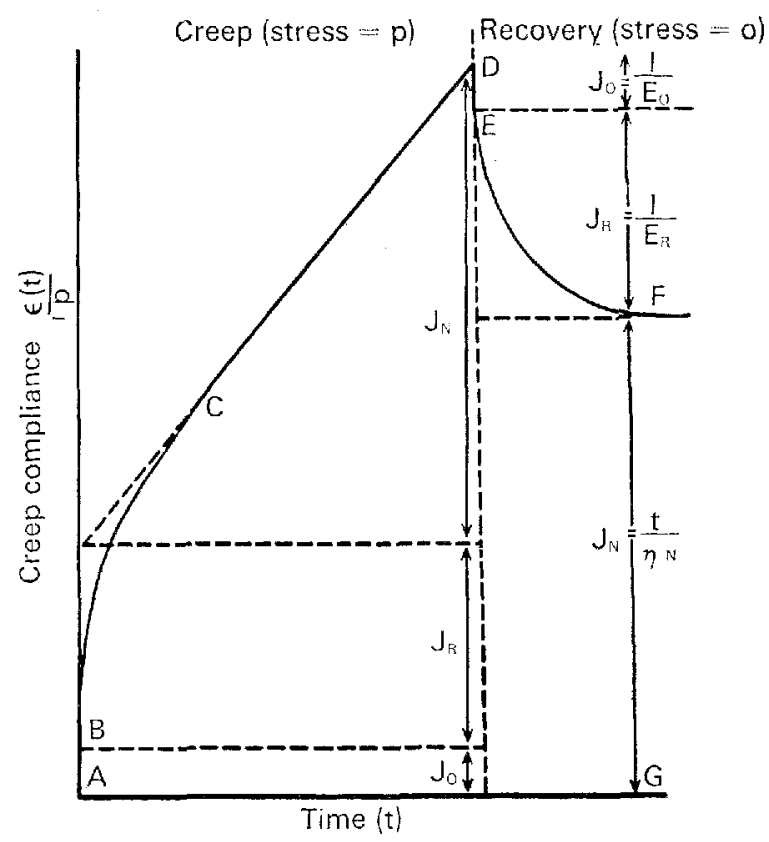

Fig. I. Model creep curve.

This region is characterized by a retarded elastic compliance $J_{R}$, where

$$
\mathrm{J}_{\mathrm{R}}=\frac{\epsilon_{\mathrm{R}}(\mathrm{t})}{\mathrm{p}}=\mathrm{J}_{\mathrm{m}}\left[\mathrm{r}-\exp \left(-\mathrm{t} / \tau_{\mathrm{m}}\right)\right]=\mathrm{J}_{\mathrm{m}}\left[\mathrm{r}-\exp \left(-\mathrm{t} / \eta_{\mathrm{m}} \mathrm{J}_{\mathrm{m}}\right)\right]
$$

and $\epsilon_{\mathrm{R}}(\mathrm{t})$ is the strain at any time $\mathrm{t}$ in the retarded elastic region, $\mathrm{J}_{\mathrm{m}}$ is the mean compliance of all the linkages undergoing rupture and redevelopment, $\tau_{\mathrm{m}}$ is the mean retardation time, $\mathrm{J}_{\mathrm{m}}\left(=\mathrm{I} / \mathrm{E}_{\mathrm{m}}\right)$ is the mean retarded elastic compliance, and $\eta_{\mathrm{m}}$ is the mean viscosity in this region. When greater detail is sought about the compliances associated with this region, equation (2) is replaced by

$$
\mathrm{J}_{\mathrm{R}}=\frac{\epsilon_{\mathrm{R}}(\mathrm{t})}{\mathrm{p}}=\sum_{\mathrm{i}} \mathrm{J}_{\mathrm{i}}\left[\mathrm{I}-\exp \left(-\mathrm{t} / \tau_{\mathrm{i}}\right)\right]=\sum_{\mathrm{i}} \mathrm{J}_{\mathrm{i}}\left[\mathrm{I}-\exp \left(-\mathrm{t} / \mathrm{J}_{\mathrm{i}} \eta_{\mathrm{i}}\right)\right]
$$

where $J_{i}\left(-1 / E_{i}\right)$, so that there is now a spectrum of retarded elastic compliances $\mathrm{J}_{1}, \mathrm{~J}_{2}, \mathrm{~J}_{3},---\mathrm{J}_{\mathrm{i}}$ and associated viscosities $\eta_{1}, \eta_{3}, \eta_{3},--\eta_{\mathrm{i}}$.

(3) A region of Newtonian compliance (CD) in which the rate of strain is constant. Once the linkages have ruptured, and are unable to reform during the time-span of the test, the micro-units are able to move past one another. The slope of CD gives the Newtonian viscosity $\eta_{\mathrm{N}}$.

The Newtonian compliance $J_{N}$ is given by

$$
J_{N}=\frac{\epsilon_{N}(t)}{p}=\frac{t}{\eta_{N}}
$$

where $\epsilon_{N}(t)$ is the strain at any time $t$ in the Newtonian region. 
If the stress is removed at $D$ then the strain decreases in two stages, initially an instantaneous elastic decrease (DE) and this is followed by a retarded elastic decrease (EF). Since part of the micro-structure was destroyed in the region $C D$, when stress was applied, recovery is never complete. The distance FG is proportional to the amount of structure which has been destroyed.

The creep compliance-time curve $A B C D$ is represented by the sum of equations (r), (2) or (3), and (4),

$$
\mathrm{J}_{\mathrm{t}}=\mathrm{J}_{0}+\mathrm{J}_{\mathrm{R}}+\mathrm{J}_{\mathrm{N}}=\mathrm{J}_{0}+\sum_{\mathrm{i}} \mathrm{J}_{\mathrm{i}}\left[\mathrm{I}-\exp \left(-\mathrm{t} / \tau_{\mathrm{i}}\right)\right]+\frac{\mathrm{t}}{\eta_{\mathrm{N}}} .
$$

This also constitutes a definition of the texture of the sample at a specified shear stress condition, since any method for assessing texture involves the response of the sample to the application of a mechanical force.

Both the compliance $J_{0}$ and $\eta_{\mathrm{N}}$ are calculated direct from the creep compliancetime curve (Fig. I). Analysis of the retarded elastic compliance region and identification of the constituent elastic moduli and viscosities involve a more complex graphical procedure (Inokuchi, 1955).

In equation (3) let

$$
\sum_{i} \mathbf{J}_{i}-\frac{\epsilon_{R}(t)}{p}=Q
$$

then

$$
\sum_{\mathbf{i}} \mathrm{J}_{\mathrm{i}} \exp \left(-\mathrm{t} / \tau_{\mathrm{i}}\right)=\mathrm{Q}
$$

so that $Q$ is the distance at any time t between the extrapolated linear part (CD) and the retarded elastic region of the creep compliance-time curve (Fig. 1). If $\log _{\mathrm{e}} \mathrm{Q}$ is plotted against $\mathrm{t}$ (Fig. 2a) a straight line should be obtained at large values of $t$. By extrapolating this linear region back to zero time, $J_{1}$ is derived as an intercept on the $\log _{\mathrm{e}} \mathrm{Q}$ axis, and $\tau_{1}$, the first retardation time, is calculated from the slope of the extrapolated line. The values of $J_{1}$ and $\tau_{1}$ are now introduced into equation (3), and if it does not give a plot which satisfactorily reproduces the retarded elastic region of the creep compliance-time curve then a second plot has to be made of $\log _{e}\left[Q-J_{1} \exp \left(-t / \tau_{1}\right)\right]$ against $t$. This plot is also linear at large values of $t$ provided $\tau_{1}>\tau_{2}$, and $J_{2}$ and $\tau_{2}$ are derived in the same way as $J_{1}$ and $\tau_{1}$. With the example quoted in Fig. $2 \mathrm{~b}$ the whole of the second plot can be approximated by a straight line so that the analysis is complete at this stage. When the calculated and experimental plots do not coincide at this stage it is necessary to make further plots of $\log _{\mathrm{e}}\left[\mathrm{Q}-\mathrm{J}_{1} \exp \left(-\mathrm{t} / \tau_{2}\right)-\mathrm{J}_{2} \exp \left(-\mathrm{t} / \tau_{2}\right)\right]$ versus $\mathrm{t}$, etc.

\section{Experimental techniques for studying creep compliance-time behaviour}

Parallel plate viscoelastometer. This method is applicable to solid and semi-solid foods which can be cut into rectangular slabs. Samples ( $S$ and $\mathrm{S}_{1}$ in Fig. 3 ) of crosssectional area $A_{r}$ and thickness $h$ are placed on either side of $a$ thin, ribbed, metal plate 

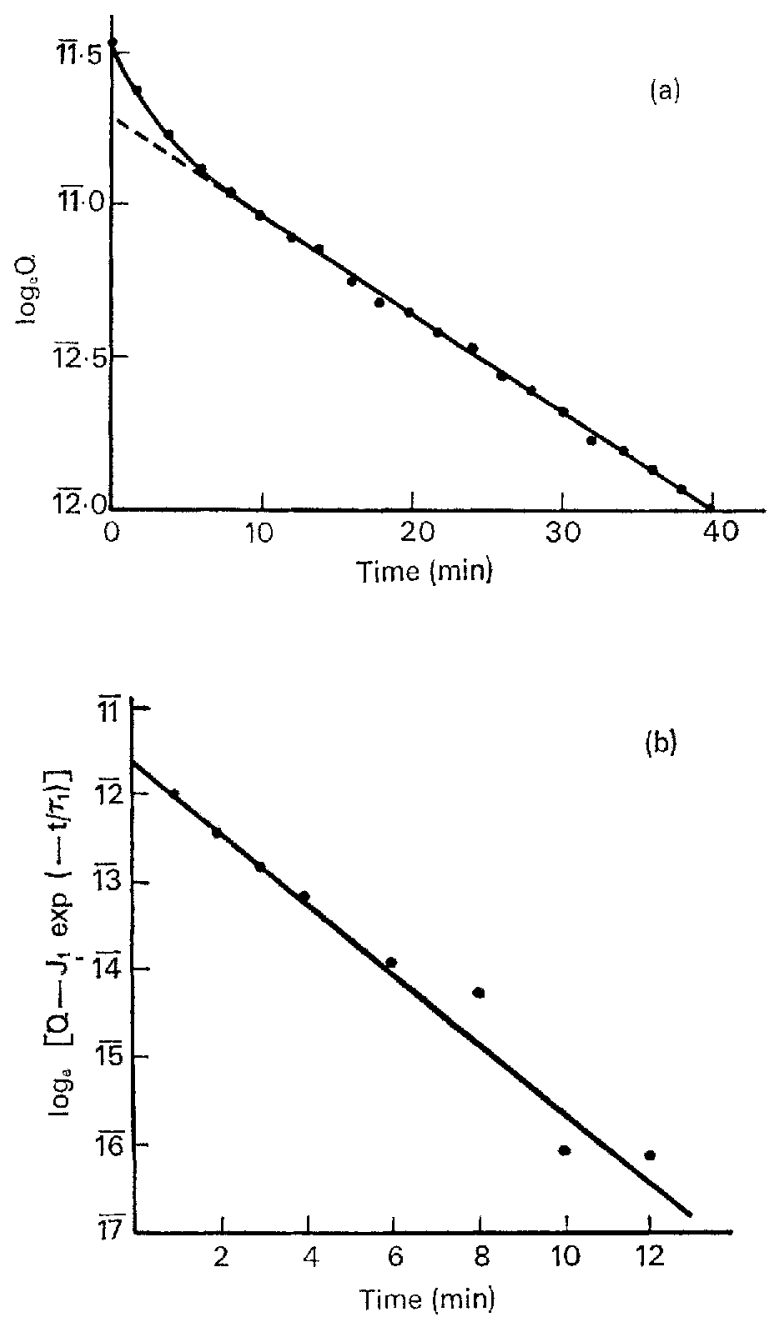

Fig. 2. a, plot of $\log _{e} Q$ v. time; b, plot of $\log _{e}\left[Q-J_{1} \exp \left(-t / \tau_{1}\right)\right]$.

D so as to form a sandwich, and this conformation is introduced into the viscoelastometer between the fixed, lower, ribbed plate $A$ and the mobile, upper, ribbed plate B. Plate B is then lowered gently by means of a screw device until it just makes contact with the upper surface of sample $S_{1}$. A weight $(\mathrm{mg})$ is placed on the balancepan $\mathrm{W}$, which is connected to plate $\mathrm{D}$ by a cord which passes over two low-friction pulleys $P$ and $P_{1}$, and this imposes a shear stress on samples $S_{1}$ and $S_{2}$. The resultant strain is determined from the movement (c) of plate $\mathrm{D}$, which can be followed by means of a travelling microscope focused on a knife edge (e.g. a thin piece of razorblade) (K) screwed into the rear of plate $D$, or by more sensitive instrumentation incorporating a differential inductance displacement transducer with a transducer meter and a T-Y recorder. The transducer is mounted on the frame of the viscoelastometer and its free armature is screwed into a hole at the rear end of plate D. 

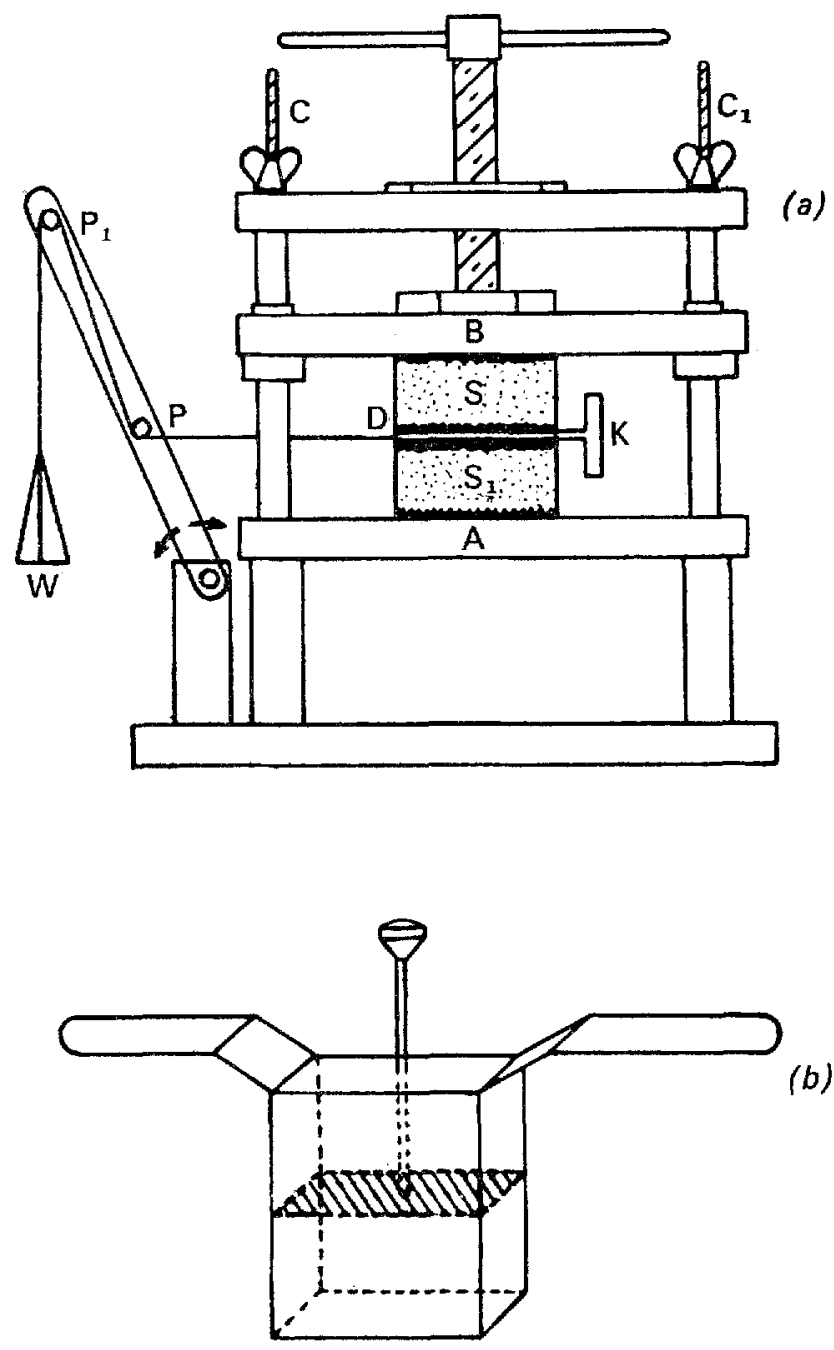

Fig. 3. Parallel plate viscoelastometer. a, creep apparatus, A, B, D, ribbed plates; C, $\mathrm{C}_{1}$, constant compression device; $\mathrm{S}, \mathrm{S}_{1}$, samples; $\mathrm{P}, \mathrm{P}_{1}$, pulleys (low friction); $W$, weight-pan; $\mathrm{K}$, knife-edge; $b$, sample cutting device.

Shear stress $(p)$ is calculated as $m g / 2 A_{r}$, and shear strain $\epsilon(t)$ as $c / h$. The greater sensitivity offered by electronic recording equipment allows one to work at lower shear stresses. This means that damage to sample structure during the test is minimized and, also, that the response of the sample is more likely to be linear viscoelastic. At higher shear stresses many foods exhibit non-linear viscoelasticity, and in this region the method of analysis is much more complex and equations (I)-(5) cannot be applied.

Compression between parallel plates. A sample of cylindrical shape is placed on a solid metal block, which is screwed into the base of a heavy metal stand, and a load (mg) is applied via a metal plate connected by a vertical rod to a platform on to $29(2) 9$ 
which slotted weights are gently lowered by a pulley system (Fig. 4). Both the metal block and the metal plate have diameters greater than that of the sample so as to ensure that the latter is subjected to pure compressional shear. The vertical rod

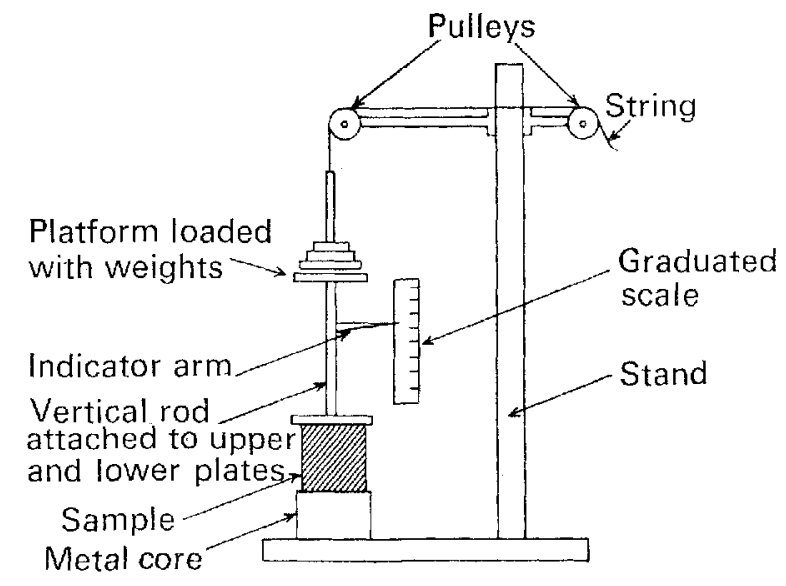

Fig. 4. Compression between parallel plates.

support of the load platform carries a horizontal indicator arm, and the change in sample height with time is followed by focusing a travelling microscope on this indicator arm. Alternatively, the electronic recording equipment described in the previous section can be used.

The stress/unit area is given by $(m g / A)\left(h_{a} / h_{b}\right)$, where $h_{a}$ and $h_{b}$ are the heights of the sample before and after loading respectively. When small loads are used $\mathrm{h}_{\mathrm{a}} \approx \mathrm{h}_{\mathrm{b}}$, so that this reduces to $\mathrm{mg} / \mathrm{A}$. Assuming a Poisson ratio of $0.5, \mathrm{p}=\mathrm{mg} 3 \mathrm{~A} /$. The shear strain $\epsilon(t)$ is equal to $d_{n} / h_{2}$, where $d_{n}$ is the deformation.

Extension testing. Extension tests apply stress in the reverse direction to compression tests. A long strip of sample is held at both ends in metal clamps (Fig. 5). One of the clamps is held stationary while the other clamp moves outwards at a constant speed so that the sample is slowly stretched. The extensometer frame

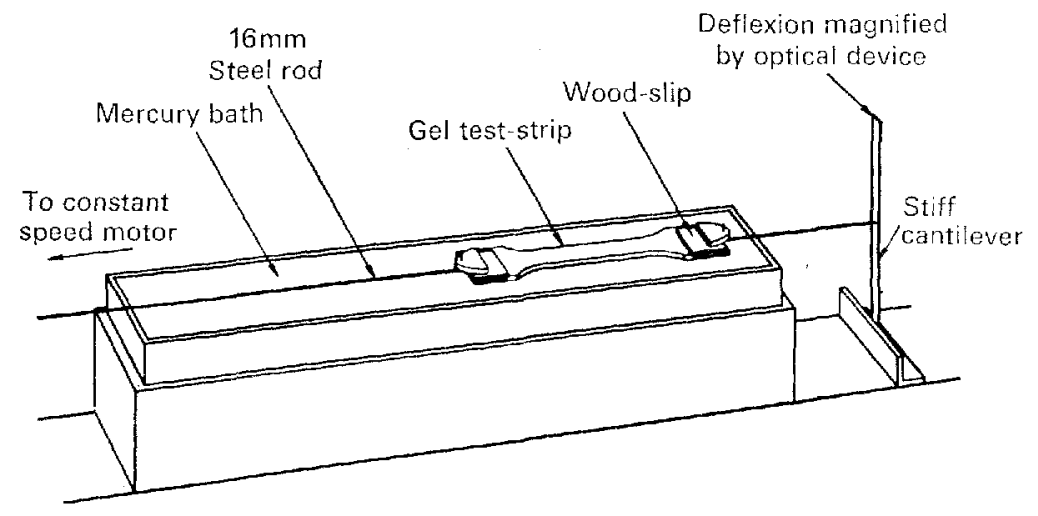

Fig. 5. Extension testing. 
usually holds the sample in a vertical plane, but in some special cases, e.g. when testing dough or gelatin gels, the frame is aligned in a horizontal plane with the sample resting on the surface of a mercury bath so that sample weight does not contribute to strain development. Strain development with time is followed either by an indicator arm and travelling microscope or with the more sensitive electronic recording equipment.

The stress is defined by $\mathrm{mg} / 3 \mathrm{~A}$, as for compression, and the strain by $\mathrm{d}_{\mathbf{n}} / \mathrm{l}_{\mathbf{a}}$, where $\mathrm{l}_{\mathrm{a}}$ is the original sample length.

Coaxial cylinder viscometer. Both fluid and semi-solid foods can be studied with a simple coaxial cylinder viscometer. (Fig. 6) The inner cylinder is suspended in the

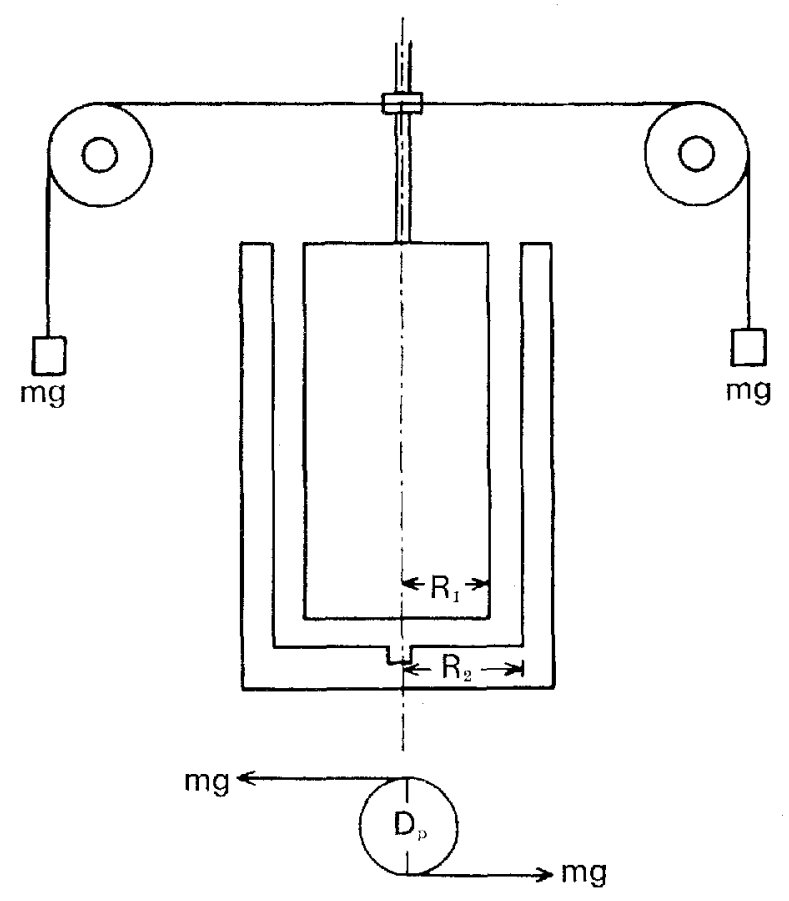

Fig. 6. Coaxial cylinder viscometer.

middle of the outer cylinder by a thin torsion wire which is attached at its upper end to a torsion head. The surfaces of both cylinders which come into contact with the sample are preferably roughened or ribbed so as to prevent the sample from slipping along these surfaces during the test. After the sample has been introduced into the gap ( $4 \mathrm{~mm}$ width in this instance) between the two cylinders, the inner cylinder is made to rotate slowly by means of a pulley and weight arrangement, or alternatively by means of an electromagnet. The angular rotation $\left(\Omega_{\mathrm{i}}\right)$ of the inner cylinder with time can be followed optically, or electronically by registering the motion of a small horizontal bar attached to the torsion wire.

The stress is given by $\left(m g D_{p}\right) / \pi\left(R_{1}+R_{2}\right) h$, where $R_{1}$ and $R_{2}$ are the respective radii of the inner and outer cylinders, $D_{p}$ is the pulley diameter, and $h$ is the height of the sample in the viscometer. The strain is defined as $R_{1} \Omega_{1} /\left(R_{2}-R_{1}\right)$. 
Semi-quantitative test methods (Table 2)

The Instron Tester. This instrument (Instron Ltd, High Wycombe, Bucks) is capable of examining samples in compression or extension. It differs from the

Table 2. Semi-quantitative test methods for foods

\begin{tabular}{|c|c|c|}
\hline \multirow{8}{*}{$\begin{array}{l}\text { Technique } \\
\text { Instron tensile tester }\end{array}$} & Applications & Reference \\
\hline & Potato & Somers (1965), Kulwich et al. $\left(196_{3}\right)$ \\
\hline & Potato chips & Bourne et al. (1966) \\
\hline & Apples & $\begin{array}{l}\text { Bourne (1965), Somers ( } 1965) \\
\text { Kulwich et al. (1963), Bourne et } \\
\text { al. (1966), Brennan et al. (1970) }\end{array}$ \\
\hline & Pears & Somers (I965), Bourne (1968) \\
\hline & Carrots & Howard \& Heinz $(1970)$ \\
\hline & Cheese, cakes & Brennan et $a l$. (1970) \\
\hline & Cherries & Bourne et al. (1966) \\
\hline \multirow{4}{*}{$\begin{array}{l}\text { General Foods Corporation } \\
\text { 'Texturometer }\end{array}$} & Wide range of foods & Szczesniak et al. (1963) \\
\hline & $\begin{array}{l}\text { Cake, lemon chiffon pudding, } \\
\text { dog food, bran flakes }\end{array}$ & Friedman et al. $(1963)$ \\
\hline & Strawberries & Szczesniak \& Smith (1969) \\
\hline & $\begin{array}{l}\text { Biscuits, apple, cheese, cake, } \\
\text { toffee, fish, banana, potato, } \\
\text { turnip, chocolate }\end{array}$ & Brennan et al. (1970) \\
\hline \multirow[t]{4}{*}{ Lee-Kramer shear press } & Meat & $\begin{array}{l}\text { Kramer et al. (1951), Kramer \& } \\
\text { Backinger (1959) }\end{array}$ \\
\hline & Peas & Angel \& Kramer (1969) \\
\hline & Fruit gels & Kramer \& Hawbecker (I966) \\
\hline & Apple, cheese & Brennan et al. (1970) \\
\hline
\end{tabular}

instruments described previously in that the stresses applied are much larger. Basically, it comprises a heavy metal frame with a moving cross-head. By attaching special grips to the upper part of the frame and the upper side of the cross-head, extension tests can be made on sample strips using controlled rates of elongation. Alternatively, a specially designed plunger can be attached to the underside of the cross-head and compression studies can then be made on samples resting on a supported table. Load cells incorporating foil-type strain gauges measure the applied load. Manual controls allow the cross-head speed to be adjusted as required. The control console incorporates a recorder for automatic plotting of force-distance curves. Other accessories are available for cyclic application of the load, and also for computing the area under the strip chart graphs.

The published literature contains several references to specially designed accessories which have been used in conjunction with this machine to test selected products, e.g. for apples, potato chips, cherries-flat compression plates, a cylindrical compression box, needles and punches of various diameters and shapes, a plate of thirty needles, a single needle, a tube cutter, a cell of a Lee-Kramer shear press; for apple--Magness-Taylor pressure tips; for meat-stainless-steel penetrometer; for carrots - a special compression device.

General Foods Corporation Texturometer. The Texturometer (Zenken Co. Ltd, Tokyo, Japan) is stated to be 'an instrument which simulates the motions of mastication in the mouth by means of a mechanical chewing arrangement. It consists basically of a sample holder, in the form of a plate or cup, and a plunger connected to an 
arm which is driven eccentrically by a 1/16 horsepower $50-60$ cycle motor. A strain gauge is located on the sample plate and, in conjunction with a high-speed recorder, it registers the force-time behaviour of the sample when subjected to the action of the plunger. The motor incorporates two pairs of tooth gears so that it provides four rates of plunger action. It has been found that a speed of forty-two bites/min gave the most reproducible results. Plungers of different materials, shapes, and sizes are now available. A flat, lucite plunger (approximately i $8 \mathrm{~mm}$ diameter and $25 \mathrm{~mm}$ length) is recommended for most foods, although a large, $50 \mathrm{~mm}$ diameter brass plunger is considered more suitable for semi-solid foods. A tooth-shaped brass plunger is claimed to give 'optimum conditions' for French-fried potatoes.

Fig. 7 shows a typical force-time curve obtained with the General Food Texturometer. Reading from right to left, the first peak represents the initial penetration, and the inverted peak below the horizontal (time) axis represents withdrawal of the plunger from the sample. Further penetration and withdrawal motions of the plunger provide an alternating series of both types of peak. All textural attributes, except viscosity, are evaluated from these traces. Viscosity is determined by using a rotating paddle attachment, instead of the plunger, which is immersed in a cup containing the sample. Brittle foods give force-time curves with many peaks, and brittleness is measured as the height of the first significant break in the peaks. Chewiness is calculated as the product of hardness, cohesiveness, and elasticity.

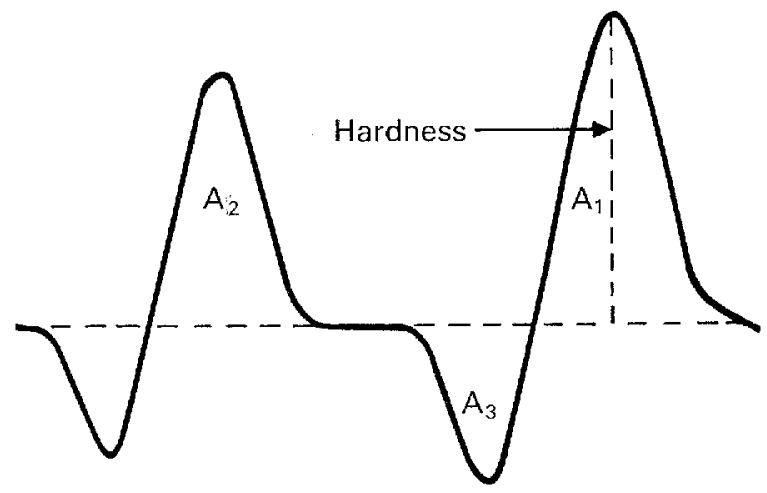

Fig. 7. Typical trace obtained with General Foods Corporation Texturometer. Hardness=height of first peak $/ V$ input; cohesiveness $=A_{2} / A_{1}$; adhesiveness $-A_{3}$.

Bourne (I968) pointed out that the plunger moves through an arc of a circle, and that the area of contact between the sample and the plunger increases on the downward stroke of the latter and it decreases as the plunger rises. He suggested that more valid curves would be obtained with an Instron tester in which an inverted load cell is fitted with a flat horizontal plate for compressing the sample. Irrespective of whether this view is correct or not, analysis of data obtained with the Instron tester or the General Foods Texturometer is more complex than has been admitted. As compression or indentation of a sample proceeds, the force/unit area changes and this is not allowed for in subsequent analysis of the data. In 
addition, the magnitude of any measurement used to assess texture depends not only on the force which is applied but also on the rate at which it is applied.

Lee-Kramer shear press. In the most recent form this instrument comprises a test cell, a sample-holder box, a hydraulic drive system, and a dynamometer. The test cell has ten bars which are 0.124 in $(3.12 \mathrm{~mm})$ thick and $0.126 \mathrm{in}(3.20 \mathrm{~mm})$ apart, and the sample box has an equivalent number of slots in its base. A sample is placed across the bars of the sample box, and the bars of the test cell are driven at a preselected speed, by means of a piston, through the sample. This results in sample compression and extrusion. The force acting on the sample is measured by compression of a proving-ring dynamometer operating within roo-5000 lb $\left(45^{\circ} 4^{-2268}\right.$ $\mathrm{kg}$ ), and it is registered on a calibrated scale. If a recorder is linked up to the shear press, a force-time curve can be obtained. Cutting and compression cells are available in addition to the shear cells.

\section{Applications of instrumental methods for evaluating food texture}

Published literature does not provide consistent evidence of statistically significant correlations between sensory evaluations of textural properties and data obtained with the Instron Tester, the General Foods Corporation Texturometer, and the Lee-Kramer shear press. This is not surprising since the mechanical action to which samples are subjected when tested with these instruments is rather complex. Recently, various foods have been tested with all three instruments (Brennan, Jowitt \& Mughsi, 1970). It was found that the Texturometer gave reproducible results only with rubber; otherwise, the results were dependent on the sample dimensions, and the reproducibility decreased with increasing hardness of the samples. With some foods, instrumentally evaluated criteria (Texturometer 'hardness' and shear press 'maximum force') correlated with sensory evaluated criteria ('firmness' and 'crispness'), but no well-defined correlation pattern emerged for all the foods that were tested. Unpublished work by Dr A. Szczesniak and her colleagues confirms that data obtained with the Lee-Kramer shear press also depend on sample dimensions.

Quantitative test methods such as creep compliance-time studies have been used to characterize the textural properties of many foods, and to study the interrelationships between structure and texture. These methods do not suffer from the limitations of the three other instruments which have been described.

Perhaps the most important application of any test method it its ability to provide data which could be used to predict consumer evaluation of textural properties. This requires a knowledge of the forces which operate when the food is consumed, so that the correct test conditions can be applied when testing the food instrumentally. Such information is essential since the measured textural properties of most foods depend on the mechanical forces to which they are subjected during testing. Work on this problem, as it applies to the assessment of the viscosity of fluid foods, was done initially by Wood ( 1968 ), and more recently in the author's laboratory. A similar study is now required of the correct test conditions for semi-solid 
and solid foods. This latter problem is infinitely more complex since it involves the study of a much larger number of textural properties.

The figures in this paper are taken from Industrial Rheology by Philip Sherman, published by Academic Press, and are reproduced with their permission.

\title{
REFERENCES
}

Angel, S. \& Kramer, A. (1969). F. Texture Studies 1, 90.

Bendall, J. R. (1951). F. Physiol., Lond. Ir4, 7 I.

Bendall, J. R. \& Davey, C. L. (1957). Biochim. biophys. Acta 26, 93.

Bourne, M. C. (1965). Fd Technol., Champaign 19, 413.

Bourne, M. C. (I968). F. Fd Sci. 33, 223.

Bourne, M. C., Moyer, J. C. \& Hand, D. B. (1966). Fd Technol., Champaign 20, 522.

Brennan, J. G., Jowitt, R. \& Mughsi, O. A. (1970). 7. Texture Studies r, I67.

Cornford, S. J., Axford, D. W. E. \& Elton, G. A. H. (I964). Cereal Chem. 4r, 2 r6.

Friedman, H. H., Whitney, J. E. \& Szczesniak, A. S. (1963). F. Fd Sci. 28, 390.

Glucklich, J. \& Shelef, L. (I $962 a)$. Cereal Chem. 39, 242.

Glucklich, J. \& Shelef, L. (1962b). Kolloidzeitschrift r81, 29.

Howard, P. L. \& Heinz, D. E. (r970). F. Texture Studies 1, 185 .

Inokuchi, K. (1955). Bull. chem. Soc. Japan 28, 453.

Kishimoto, A. \& Maekawa, E. (1962). Bull. fap. Soc. scient. Fish., 28, 803.

Kramer, A. \& Backinger, G. (1959). Food 28, 85.

Kramer, A., Burckhardt, G. J. \& Rogers, H. P. (1951). Canner 112, 34.

Kramer, A. \& Hawbecker, J. V. (1966). Fd Technol, Champaign 20, 209.

Kulwich, R., Decker, R. W. \& Alsmeyer, R. H. (1963). Fd Technol, Champaign r7, 201.

Mohsenin, N. N., Cooper, II. H. \& Tukey, L. D. (1963). Trans Am. Soc. agric. Engrs 6, 85.

Mohsenin, N. N. \& Göhlich, H. (I962). F. agric. Fngng Res. 7, 300.

Prentice, J. H. (1968). Monogr. Soc. chem. Ind. no. 27, p. 265.

Prentice, J. H. \& Chapman, H. R. (I969). F. Dairy Res. 36, 269.

Shama, F. \& Sherman, P. (1966). F. Fd Sci. 31, 699.

Shama, F. \& Sherman, P. (1968). Monogr. Soc. chem. Ind. no. 27, p. 77.

Shama, F. \& Sherman, P. (1970). J. Texture Studies I, 196.

Shaw, D. J. (1963). In Rheology of Emulsions p. 125 [P. Sherman, editor]. London: Pergamon Press.

Shelef, L. \& Bousso, D. (1964). Rheol. Acta 3, 168.

Sherman, P. (I970). Industrial Rheology: with particular reference to foods, pharmaceaticals and cosmetics. London: Academic Press.

Shimizu, 'T., Fukawa, H. \& Ichiba, A. (1958). Cereal Chem. 35, 34.

Somers, F. (1965). F. Fd Sci. 30, 922.

Sone, T. (1961). F. phys. Soc. Fapan 16, 961.

Sone, 'T., Fukushima, M. \& Fukada, E. (1962). Proc. int. Dairy Congr. xvi. Copenhagen Vol. B, p. 165.

Szczesniak, A. S. (1963). F. Fid Sci. 28,385 .

Szczesniak, A. S., Brandt, M. A. \& Friedman, H. H. (1963). F. Fd Sci. 28, 397.

Szczesniak, A. S. \& Smith, B. J. (1969). J. Texture Studies 1, 65.

Ward, A. G. \& Cobbett, W. G. (r g68). Monogr. Soc. chem. Ind. no. 27, p. ror.

Whitehead, J. \& Sherman, P. (1967). Fd Technol., Champaign 21, 152x.

Wood, F. W. (1968). Monogy. Soc. chem. Ind. no. 27, p. 40.

\section{Some aspects of the measurement of flavour}

\author{
By D. G. LAND, Food Research Institute, Norwich
}

The nutritional importance of those constituents of food which contribute to flavour is not due to their fulfilling a bodily requirement, but to their influence on acceptance and, therefore, consumption of food. Consequently, flavour is a factor 